University of Nebraska - Lincoln

DigitalCommons@University of Nebraska - Lincoln

2009

\title{
A New Filatima Busck (Lepidoptera: Gelechiidae) Associated with Lupine and Early Herbivore Colonization on Mount St. Helens
}

\author{
David Adamski \\ Department of Entomology, National Museum of Natural History, Smithsonian Institution, P.O. Box 37012, \\ MRC 168, Washington, D.C., 20013- 7012, U.S.A., adamskid@si.edu \\ Jennifer L. Apple \\ Department of Biology, SUNY Geneseo, 1 College Circle, Geneseo, New York 14454, U.S.A., \\ applej@geneseo.edu \\ John G. Bishop \\ School of Biological Sciences, Washington State University, 14204 NE Salmon Creek Avenue, Vancouver, \\ Washington 98686, U.S.A., bishopj@vancouver.wsu.edu
}

Follow this and additional works at: https://digitalcommons.unl.edu/systentomologyusda

Part of the Entomology Commons

Adamski, David; Apple, Jennifer L.; and Bishop, John G., "A New Filatima Busck (Lepidoptera: Gelechiidae) Associated with Lupine and Early Herbivore Colonization on Mount St. Helens" (2009). USDA Systematic Entomology Laboratory. 49.

https://digitalcommons.unl.edu/systentomologyusda/49

This Article is brought to you for free and open access by the Entomology Collections, Miscellaneous at DigitalCommons@University of Nebraska - Lincoln. It has been accepted for inclusion in USDA Systematic Entomology Laboratory by an authorized administrator of DigitalCommons@University of Nebraska - Lincoln. 


\title{
A NEW FILATIMA BUSCK (LEPIDOPTERA: GELECHIIDAE) ASSOCIATED WITH LUPINE AND EARLY HERBIVORE COLONIZATION ON MOUNT ST. HELENS
}

\author{
David Adamski, Jennifer L. Apple, and John G. Bishop
}

(DA) Department of Entomology, National Museum of Natural History, P.O. Box 37012, Smithsonian Institution, Washington, DC 20013-7012, U.S.A. (e-mail: David.Adamski@ars.usda.gov); (JLA) Department of Biology, SUNY Geneseo, 1 College Circle, Geneseo, New York 14454, U.S.A. (e-mail: applej@geneseo.edu); (JGB) School of Biological Sciences, Washington State University, 14204 NE Salmon Creek Avenue, Vancouver, Washington 98686, U.S.A. (e-mail: bishopj@ vancouver.wsu.edu)

Abstract. - Filatima loowita, n. sp. is described from the Pumice Plain on Mount St. Helens in Washington, United States. An apparent specialist on lupine, early instars feed as leaf-miners, while later instars tie leaflets together into silken tunnels and feed externally, mainly on the leaf tissue. The larvae make webbed tunnels, which extend from the root bundles to the uppermost leaves of the plant. Illustrations are provided of the adult male and female genitalia, and chaetotaxal maps of the last-instar larva, supplemented with scanning electron micrographs and images of the host on the volcano.

Key Words: colonization, herbivory, Lupinus

Mount St. Helens is an active stratovolcano in the southwestern part of Washington in the Pacific Northwest region of the United States. It is about $154 \mathrm{~km}$ south of Seattle and about $83 \mathrm{~km}$ northeast of Portland, Oregon. The volcano is part of the Cascade Range and the Cascade Volcanic Arc, which extends from northern California to British Columbia, Canada. The Cascade Volcanic Arc forms a segment of the Pacific Ring of Fire that includes more than 160 active volcanos.

On May 18, 1980, Mount St. Helens erupted and caused the most economically destructive volcanic event in the history of the United States. The erup-

* Accepted by David R. Smith tion generated a massive avalanche of debris, reducing the elevation of the mountain's summit from $2,950 \mathrm{~m}$ to $2,550 \mathrm{~m}$, and replaced it with a large horseshoe-shaped crater about $1.5 \mathrm{~km}$ wide. Two years after the eruption, the United States Government established the Mount St. Helens National Volcanic Monument, a $445 \mathrm{~km}^{2}$ area around the volcano and within the Gifford Pinchot National Forest, for research and education. Inside the monument the environment was allowed to respond naturally to the disturbance.

The 1980 eruption of Mount St. Helens exterminated all flora and fauna from the area (del Moral 1993, del Moral and Bliss 1993, del Moral et al. 1995) and created a $60 \mathrm{~km}^{2}$ region of primary 
successional habitat (the Pumice Plain), mostly on the volcano's north slope. Outside of this zone, signs of the eruption decreased in proportion to increased distance from the volcano. Within this outer region remnant, individuals of many plant species survived in sheltered pockets (Fagan and Bishop 2000). In 1981, Fagan and Bishop (2000) observed that the plant species Lupinus lepidus Douglas ex Lindl. var. lobbii (A. Gray ex S. Watson) (Fabaceae) had colonized the otherwise barren north slope of the volcano (Fig. 17) from remnant populations elsewhere on the volcano (Fagan and Bishop 2000). In fact, Lupinus lepidus var. lobbii, a native perennial and nodulating legume, was the earliest angiosperm to colonize the Pumice Plain (Wood and del Moral 1987).

For several years the lupine population spread rapidly and was the most successful colonist on pumice and rock substrates (del Moral and Bliss 1993). During seasonal 3-month growing periods, lupines on Mount St. Helens endured infestations by several insect herbivores, the most important of which include a caudex-boring olethreutine, Hystricophora sp. (Tortricidae) and a leaf-webbing species of Filatima (Gelechiidae) which is described herein.

Filatima are Holarctic in distribution, and more than 100 described species are known. However, their greatest diversity is in the semiarid areas of western United States and Mexico. Most species of Filatima are medium-sized grayish brown moths with a few slightly darker oblique markings outside of and traversing the discal cell of the forewing, but some species are black, white, or pale brownish yellow with highly contrasting markings. Larvae of Filatima are leaftiers on Acacia Mill., Amorpha L., Astragalus L., Cercidium Tul., Glycyrrhiza L., Leucaena Benth, Lupinus L., Mimosa L., Prosopis L., Robinia L.,
Thermopsis Robt. Brown, Vicia L. (Fabaceae); Prunus L., Purshia DC. (Rosaceae); Ribes L. (Grossulariaceae); Vaccinium L. (Ericaceae); Phoradendron Nutt. (Loranthaceae); Salix L. (Salicaceae); and Betula L. (Betulaceae).

Characters used previously to characterize Filatima are listed by Hodges and Adamski (1997) and include: male hind wing often with "curtain scales" (Busck 1939, Clarke 1947) from wing base to between $\mathrm{Sc}+\mathrm{R}_{1}$ and $\mathrm{Rs}$, other sex scales on posterior half of discal cell; male genital capsule enclosed within eighth segment; costal lobe of valva elongate and narrow; saccular lobe of each valva asymmetric; aedeagus with lateral sclerite and several other internal sclerites; ventral surface of eighth tergum with paired, basolateral hair pencils, dorsal surface usually with prominent, long, anteriorly directed scales arising posteromedially; female genitalia with antrum sclerotized or membranous; inception of ductus seminalis on anterior part of accessory bursa; posterior part of corpus bursae and accessory bursae often with dense microtrichiae.

The purpose of this paper is to make available the name Filatima loowita, n. sp., to describe its adult and larval stages, and to document its association with lupine in the northwestern United States.

\section{Materials and Methods}

Information on the natural history of $F$. loowita was obtained as part of a broader study of the insect herbivores of L. lepidus (Fabaceae) on Mount St. Helens. Collections were made from our study site in a region of the Mount St. Helens National Volcanic Monument know as the Pumice Plain, which is located between the crater and Spirit Lake at $46^{\circ} 14^{\prime} 53.73^{\prime \prime} \mathrm{N}, 122^{\circ} 10^{\prime} 00.87^{\prime \prime} \mathrm{W}$ at an elevation of $1,106 \mathrm{~m}$ (3,628 feet). Larvae were field collected during the period from early July to the end of 


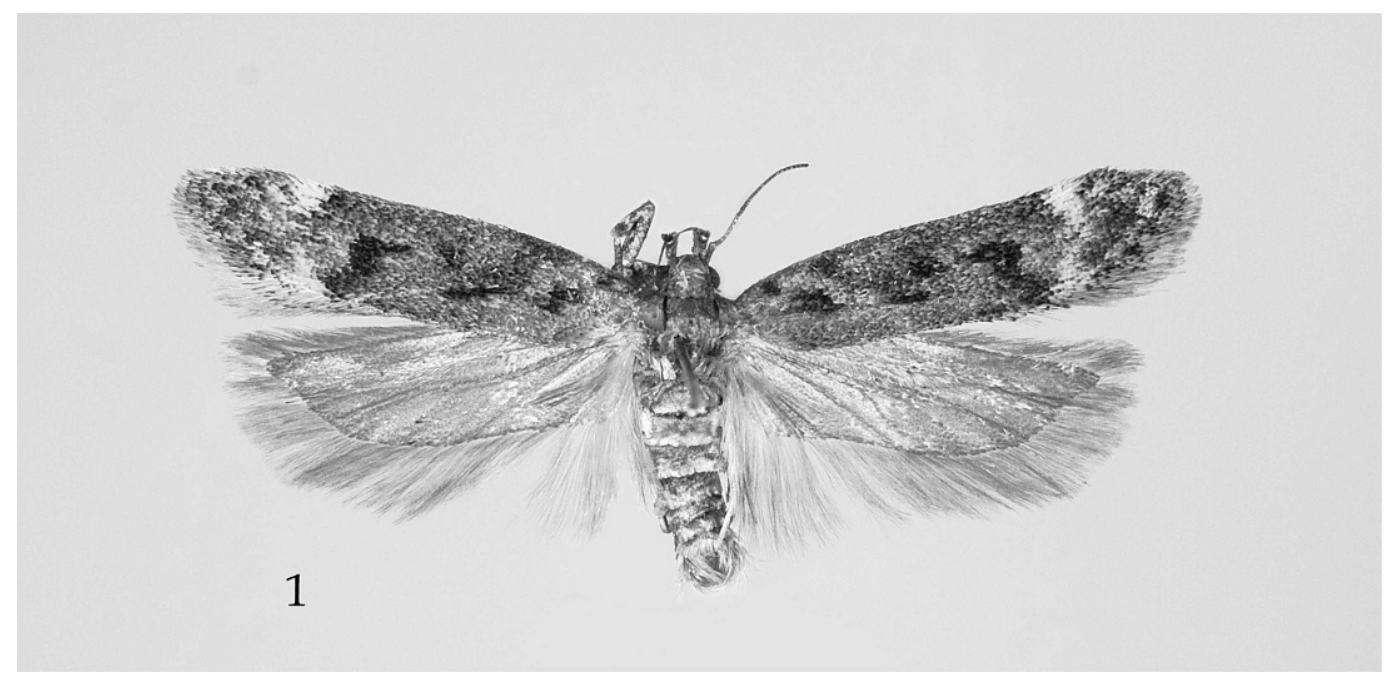

Fig. 1. Filatima loowita, holotype (prior to dissection).

August and reared in the laboratory to obtain an association between the immature stages and the adult. Additional adult specimens were collected by sweeping and using blacklight traps within the study area. Larvae were boiled in $\mathrm{H}_{2} \mathrm{O}$ and preserved in $70 \%$ EtOH. For SEM study, larvae were cleaned in a fullstrength solution of all-purpose cleaner (Formula 409TM detergent) and subsequently dehydrated in increasing concentrations of alcohol to absolute alcohol. After dehydration, specimens were critical point dried using a Tousimis critical point dryer, mounted on SEM stubs, and coated with gold-palladium (40/60\%) using a Cressington sputter coater. The ultrastructure of the larva and pupa was studied with an Amray 1810 scanning electron microscope at an accelerating voltage of $10 \mathrm{kV}$.

Type material and/or authoritatively identified specimens of adults and genitalia of all Filatima in America north of Mexico were examined in the United States National Museum of Natural History, Smithsonian Institution, Washington, DC (USNM). Gross morphological observations and measurements of the larva and forewings were made using a dissecting microscope (reflected light) with a calibrated micrometer. Genitalia were dissected as described by Clarke (1941) except mercurochrome and chlorazol black were used as stains. The Methuen Handbook of Colour (Kornerup and Wanscher 1978) was used as a color standard. All types and voucher specimens of immature stages generated from this study are deposited in the USNM. Host data for Filatima were taken from label data of specimens in the USNM collection and searched in databases provided in Powell (2008) and Robinson et al. (2002). Nomenclature of plants follows the USDA Germplasm Resources Information Network GRIN (2007). Nomenclature of the larval chaetotaxy follows Stehr (1987). Nomenclature of the sensilla of the larval antenna follows Dethier (1941). Nomenclature of the sensilla of the larval maxillary palpus follows Grimes and Neunzig (1986). The senior author is the authority for the species described herein.

Filatima loowita Adamski, n. sp. (Figs. 1-16, 20, 22)

Diagnosis.-Filatima loowita is most similar to $F$. shastaella (Gaede), described from California, by sharing a similar 


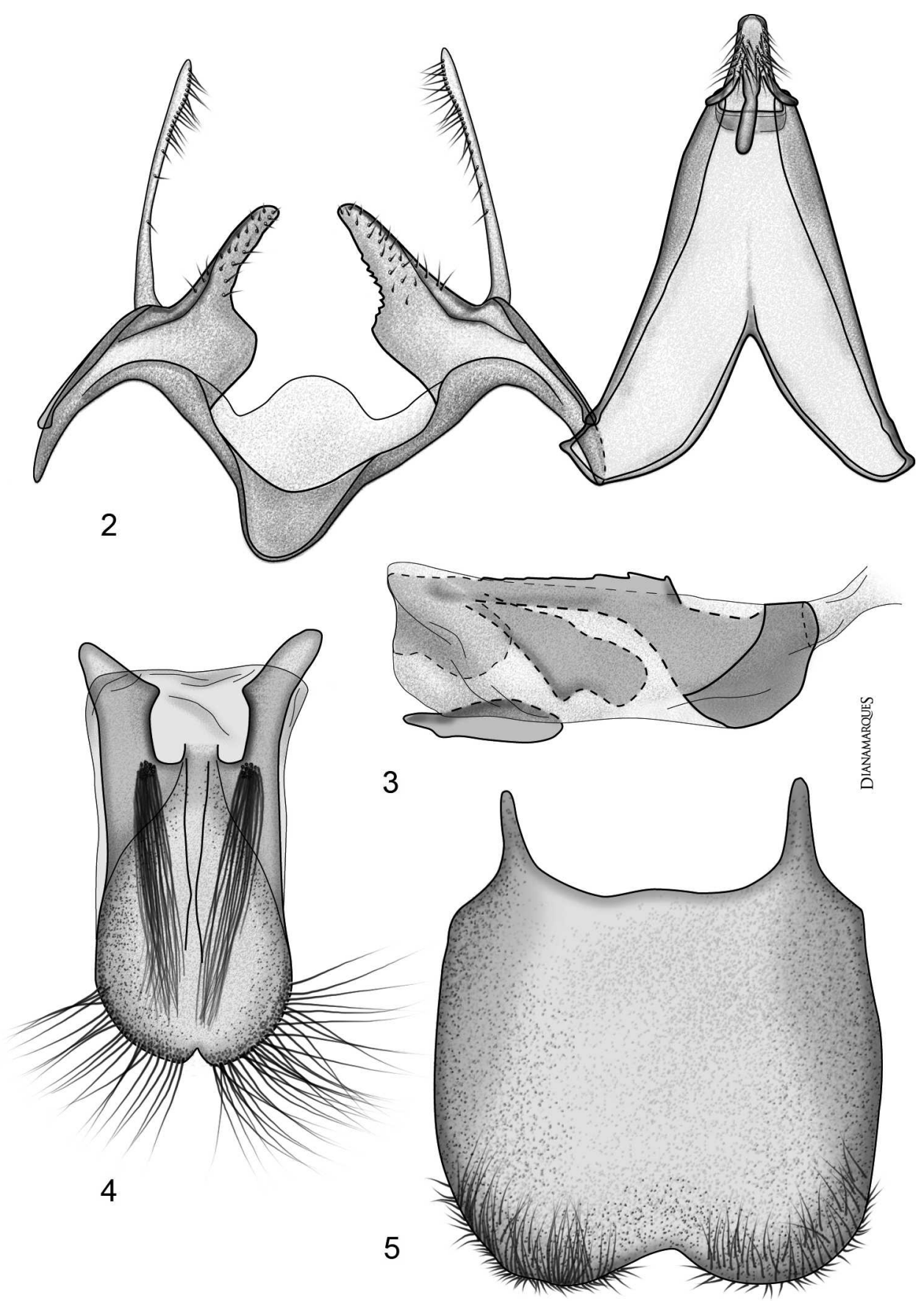

Figs. 2-5. Male genitalia and eighth tergum and sternum of Filatima loowita. 2, Genital capsule (sternal elements on left). 3, Aedeagus. 4, Eighth tergum. 5, Eighth sternum.

forewing pattern, but it differs from the latter species by having narrower and more slanted lobes of the vinculum, a larger cornutus of the vesica, and female with pendular lobes arising from membrane anterior to the eighth sternum.

Specimens of Filatima xanthuris (Meyrick) from Silverton, Colorado and 


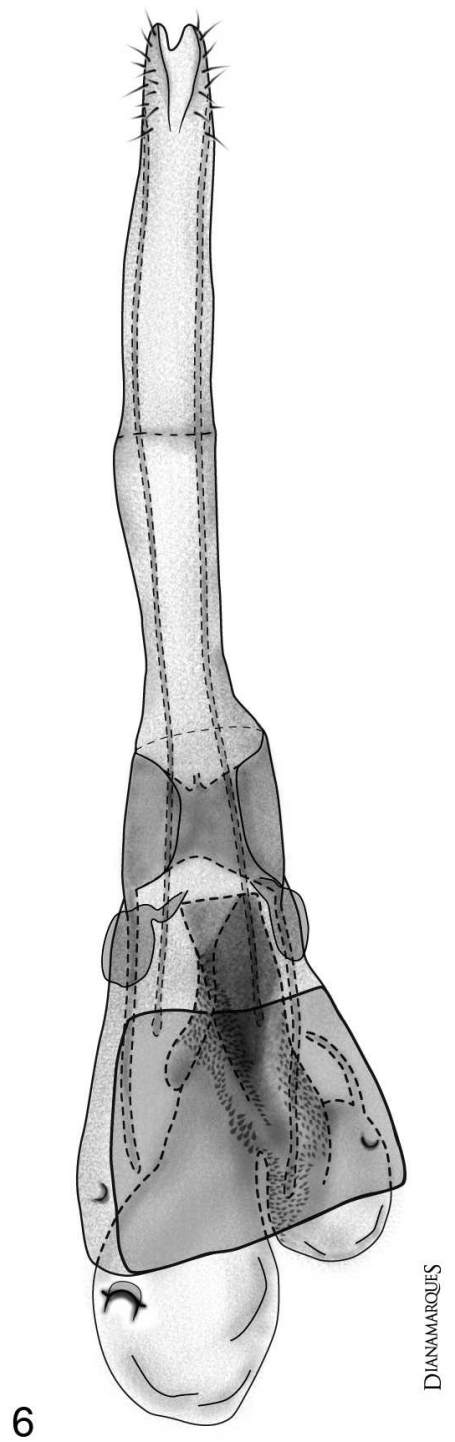

Fig. 6. Female genitalia of Filatima loowita.

Pullman, Washington were examined in the USNM. Filatima xanthuris feeds on Lupinus and is similar in wing pattern to $F$. loowita, but it differs from $F$. loowita by having more asymmetric lobes of the vinculum, a free digitate sclerite extending from base of aedeagus, and the posterior end of corpus bursae and accessory bursae with many hairlike microtrichiae. Images of the pinned adult specimen and male and female genitalia of Filatima xanthuris are found in
Hodges and Adamski (1997). Filatima xanthuris and $F$. loowita are the only known species of Filatima that feed on Lupinus.

Description.-Head: Vertex and frontoclypeus brownish gray; labial palpus extending well beyond vertex, outer and inner surfaces of labial palpus with segment-1 and basal half of segment-2 pale brownish gray, gradually darkening to gray distally; ventral surface of segment-2 with scales divergent, forming broad, V-shaped groove; segment-3 gray; scape and flagellum gray; ocelli present; scales of proboscis pale brownish gray.

Thorax: Tegula with scales pale gray marginally tipped with gray; mesonotum gray; profemur dark gray with pale-gray scales near distal margin, meso- and metafemora pale gray intermixed with gray scales, tibia gray with patches of pale-gray scales near midlength and distal margin; tarsomeres gray with pale-gray scales along distal margins. Forewing (Fig. 1): Length 7.3-10.9 mm $(\mathrm{n}=11)$, pale gray intermixed with some scales tipped with dark gray and a few grayish orange scales; costa with two gray scale patches on basal $1 / 6$; cell with 4 gray markings, 1 spot near base, 1 spot near midlength, broad oblique streak extending from near distal end to $\mathrm{CuP}$, and 1 narrow gray streak along $\mathrm{CuP}$ basoposterior to midcell spot; white or pale gray subapical spot narrowed posteriorly into irregular line, outwardly rounded medially, extending from costa to tornus; apical area gray except pale gray along costa; fringe pale gray. Ventral surface gray. Hind wing: pale gray; undersurface with pale-yellow curtain scales within area of cell.

Abdomen (Figs. 4-5): Eighth tergum elongate, slightly narrowed lateromedially, cleft distomedially, with pair of mediolateral bundles of hair pencils; eighth sternum at least twice as wide as tergum, cleft distomedially, with two digitate projections on anterior end, 

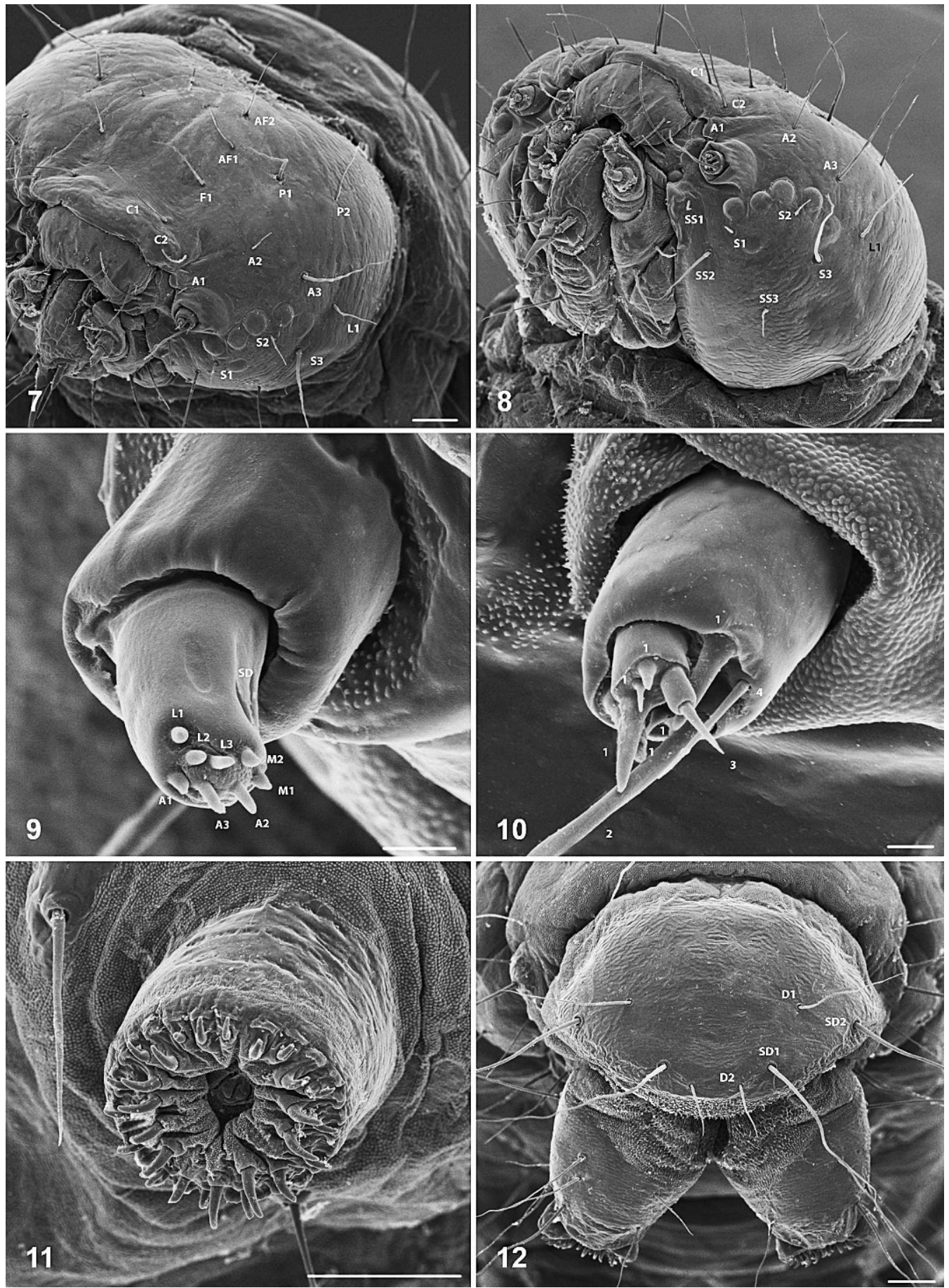

Figs. 7-12. Scanning electron micrographs of larva of Filatima loowita. 7, Head, frontolateral view. Scale $=100 \mu \mathrm{m} .8$, Head, ventrolateral view. Scale $=100 \mu \mathrm{m}$. 9, Right maxillary palpus, frontodorsal view. A2 = sensillum styloconicum; A1, A3, M1, M2, L1, L2, L3 = sensilla basiconica; $\mathrm{SD}=$ sensillum digitiforma. Scale $=10 \mu \mathrm{m}$. 10, Left antenna, frontodorsal view. $1=$ sensilla basiconica; $2=$ sensilla trichoidea; $3=$ sensilla styloconica; $4=$ sensilla chaetica. Scale $=10 \mu \mathrm{m}$. 11, Left proleg on A6. Scale $=$ $100 \mu \mathrm{m} .12$, Anal plate, caudal view. Scale $=100 \mu \mathrm{m}$. 


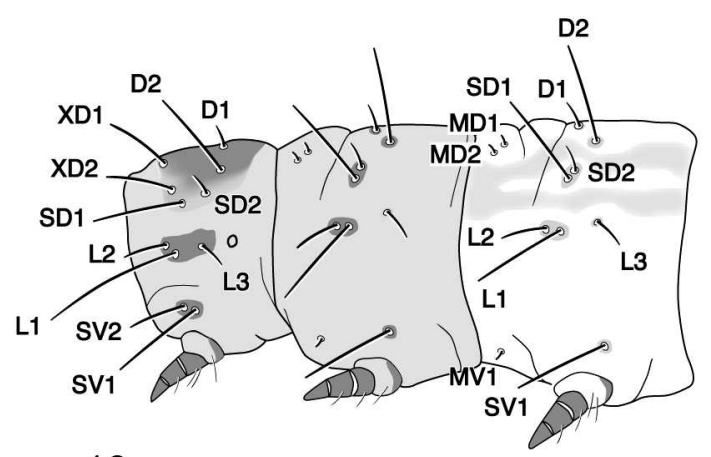

13

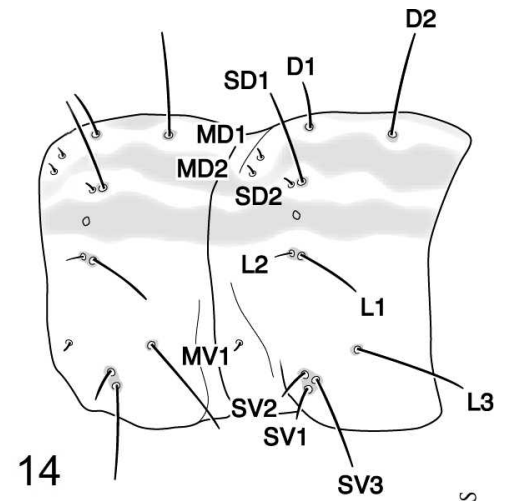

宸

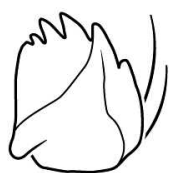

15

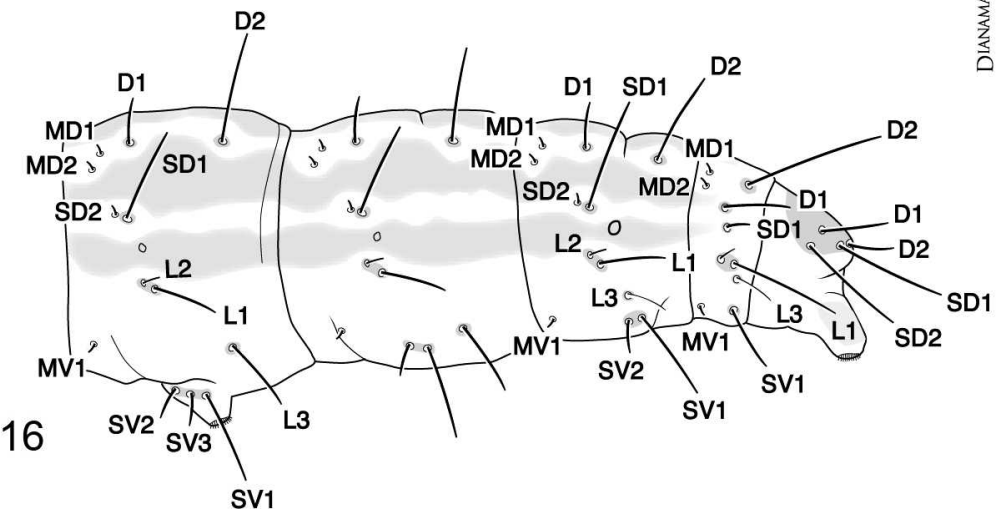

Figs. 13-16. Chaetotaxal maps and mandible of Filatima loowita. 13, T1-T3, lateral view. 14, A1-A2, lateral view. 15, Left mandible, view of inner surface. 16, A6-A10, lateral view.

slightly indented from lateral margin. Male Genitalia (Figs. 2-3): Genital capsule enclosed within eighth segment; uncus narrow, setose, hood-shaped; gnathos narrow and recurved; tergum gradually widened anteriorly (in situ) forming two broad, divergent arms; vinculum extending laterally from median lobe, forming two recurrent arms; saccular lobes of valva slightly asymmetrical, widened laterally, with acuminate apices; costal lobes of valva digitate and distally setose; aedeagus about as long as tegumen, slightly widened distally, with cylindrical base, extending along one side distally forming dilated apical process; dorsolateral margin of sclerite from above base to apical process shallowly serrate; short, elongate sclerite on opposite side near apex; vesica with an elongate, subtriangular-shaped cornutus near middle. Female Genitalia (Fig. 6): Ovipositor telescopic, with two membranous subdivisions, papillae anales setose; apophyses posterioris about $31 / 3$ times length of apophysis anteriores; eighth tergum cylindrically curved ventrally, forming two broadly rounded, opposable, bandlike arms; ostium within membrane near ventroanterior margin of eighth segment, juxtaposed by two small pendular lobes originating from membrane near ventrolateral margin of anterior end of eighth segment; posterior half of ductus bursae sclerotized, anterior half membranous, sparsely lined with spicules; accessory bursa about $1 / 2$ size of corpus bursae, with inception of ductus seminalis on lateroposterior end; corpus bursae with signum crescent-shaped, with 

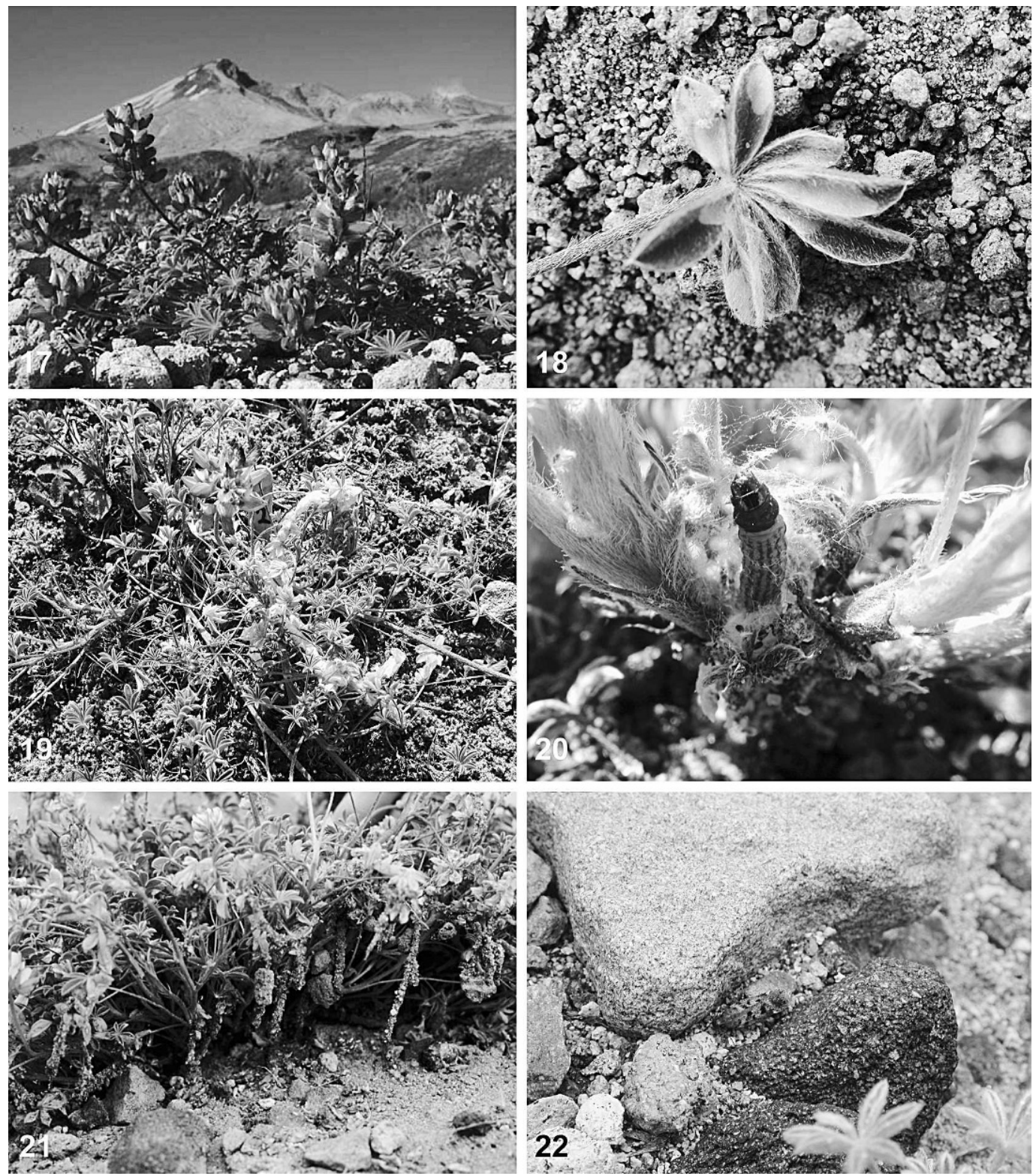

Figs. 17-22. Habitat of Lupinus lepidus var. lobbii, and larva and adult of Filatima loowita on the Pumice Plain of Mount St. Helens. 17, Lupinus lepidus in foreground, and the crater of Mount St Helens in background. 18, Leaf-mines of early-instar larva of F. loowita. 19, Above-ground webbing. 20, Larva protruding from opening of its silken tunnel. 21, Subterranean silken tunnels. 22, Adult resting.

short spinelike process extending at near right angle from each end.

Material examined.-Holotype $\delta$ : "WASHINGTON: M[oun]t S[ain]t Helens National Volcanic Monument, $46^{\circ} 14^{\prime} 53.73^{\prime \prime} \mathrm{N}, 122^{\circ} 10^{\prime} 00.87^{\prime \prime} \mathrm{W}, 3,628$ feet, 18 June 2004, Pumice Plain-882, J. Bishop, (sweeping)," "Genitalia Slide by D. Adamski, USNM 83340" [green label]. Deposited in USNM. Paratypes (11 $\hat{\delta}, 4$ क): 1 s, "WASHINGTON: M[oun]t S[ain]t Helens National Volcanic Monument, $46^{\circ} 14^{\prime} 53.73^{\prime \prime} \mathrm{N}, 122^{\circ} 10^{\prime} 00.87^{\prime \prime} \mathrm{W}$, 3,628 feet, 5 June 2003, Pumice Plain 
365, Jennifer Apple, (sweeping)"; “ $\delta$ Genitalia Slide by D. Adamski, USNM 83341" [green label]; 1 $\hat{\sigma}$, as above except, “18 June 2003, Pumice Plain-397,” “ ‘ Genitalia Slide by D. Adamski, USNM 83342" [green label]; 1 oे, as above except, "5 June 2003, Pumice Plain-364," “ $\hat{\sigma}$ Genitalia Slide by D. Adamski, USNM 83343" [green label]; 1 ๙े, as above except, "19 August 2002, Pumice Plain-207, (larva on Lupinus), Eclosed 7 October 2002," " क Genitalia Slide by D. Adamski, USNM 83344" [green label]; 1 $\delta$, as above except, "19 June 2002, Pumice Plain-191, (sweeping)," “ ‘ Genitalia Slide by D. Adamski, USNM 83345" [green label]; 1 ई̊, as above except, "9 July 2003, Pumice Plain-458, (sweeping)," “๙ Genitalia Slide by D. Adamski, USNM 83346" [green label]; 1 §, as above except, "17 July 2002, Pumice Plain-203, (light trap)," “ $\hat{\sigma}$ Genitalia Slide by D. Adamski, USNM 83347' [green label]; 1 $\hat{\sigma}$, as above except, "Pumice Plain-202," " ‘े Genitalia Slide by D. Adamski, USNM 83348" [green label]; 1 ô, as above except, "9 July 2003, Pumice Plain-457'; 1 oे, as above except, "18 June 2002, reared from egg, Pumice Plain-924, Eclosed 3 December 2003"; 1 §, as above except, "18 July 2002, Pumice Plain-294, larva on Lupinus lepidus, Eclosed 18 July 2003"; 1 오 , as above except, "9 July 2003, Pumice Plain459 (sweeping)," "q Genitalia Slide by D. Adamski, USNM 83349" [green label]; 1 ㅇ, as above except, "18 June 2003, Pumice Plain-394," " + Genitalia Slide by D. Adamski, USNM 83350"' [green label]; 1 + , as above except, "8 July 2004, Pumice Plain-937”; 1 , as above except, "18 July 2002, Pumice Plain-298, larva on Lupinus lepidus, Eclosed 18 July 2003." All paratypes deposited in USNM.

Larva (Figs. 7-16, 20).--Length 8.2$15.1 \mathrm{~mm}(\mathrm{n}=9)$. Body smooth, pale grayish green with T1-T2 reddish brown; dorsal, subdorsal, and lateral lines pale reddish brown, extending from $\mathrm{T} 3$ to anterior portion of A9; head capsule, prothoracic shield, and thoracic legs dark reddish brown; pinacula brown; anal plate yellowish brown.

Head (Figs. 7-10, 15): Hypognathous; epicranial suture short, bisecting adfrontal sclerites apically; adfrontal sclerites meeting at base of epicranial notch; notch moderately deep, forming two adjacent hemispheres; integument shallowly wrinkled; AF2s slightly above or even with apex of frons; AF1 and F1 in straight line (parallel with longitudinal axis), equal in lengths, slightly shorter than AF2; $\mathrm{C} 1$ about 1/3 longer than $\mathrm{C} 2$; P1 laterad and slightly dorsal to AF1, about $4 \times$ as long as P2; P2 dorsolateral to P1 and in near straight line with A2 and A1; A3 dorsolateral to A2, about 5-6× longer than A2, closer to L1 than to $\mathrm{S} 3$; A1 slightly shorter than A2; six stemmata in irregular C-shaped pattern, with stemma 3-4 approximate and perpendicular to stemma 5-6; S-group setae in circular line through stemmatal area, with S1-S2 much shorter than S3; SS3 closer to $\mathrm{S} 3$ than to $\mathrm{S} 1, \mathrm{SS} 2$ closer to $\mathrm{S} 1$ than to SS1, with SS1 lateral to mandible and under antennal base; mandible with five teeth along distal margin, three large median teeth and one small tooth at each end; mandibular setae subequal in length; labrum with six pairs of setae, two median pairs subequal in length, two ventromarginal pairs subequal in length, and two lateromarginal pairs subequal in length; sensilla of maxillary palpus as figured (Fig. 9); antennal sensilla as figured (Fig. 10); spinneret at least twice as long as adjacent palpi (Fig. 8).

Thorax (Fig. 13): T1 with L-group trisetose on elongate pinaculum anterior to spiracle; L1 about $4 \times$ longer than L2 and L3, posteroventral to L2 and in horizontal line with (parallel with longitudinal axis) or slightly ventral to L3; spiracle with diameter twice that of spiracles on A1-A7; SV1 slightly longer than SV2; V1s slightly posterior to coxal 
margin (not shown); shield with SD1 slightly longer than XD2 and XD1 slightly posterior to both setae; XD2 slightly closer to SD1 than to XD1 or equidistant between both setae; SD2 about as long as D1, slightly closer to $\mathrm{SD} 1$ than to $\mathrm{XD} 2$, anterior to $\mathrm{D} 2$ and D1; D2 about as long as SD1, slightly closer to XD2 than to XD1 or equidistant to both setae and in line with D1 perpendicular with longitudinal axis; D1 closer to longitudinal body axis than XD1; T2-T3 (Fig. 13): D2 about $3 \times$ length of $\mathrm{D} 1$, on larger pinaculum than D1; MD1 and MD2 dorsoanterior to SD-group setae; SD1 about $3 \times$ length of $\mathrm{SD} 2$, both on same pinaculum anterior to D-group setae; L1 about twice as long as L2, on same pinaculum, anterior to SD-group setae; L3 slightly shorter than L2, slightly anterior to or in line with SV1 perpendicular with longitudinal axis; MV1 anterior or slightly anteroventral to SV1; V1s on T2 twice distance apart as distance between $\mathrm{V} 1 \mathrm{~s}$ on $\mathrm{T} 1$ and $3 \times$ distance apart on T3, setae anterior to line between anterior margins of coxae; A1-A2 (Fig. 14), D2 about 2$2.5 \times$ longer than $\mathrm{D} 1$, slightly ventral to D1; MD1 and MD2 dorsoanterior to SD-group setae; SD1 slightly dorsoposterior to spiracle on A1, with SD1 dorsal or slightly dorsoanterior to spiracle on A2; SD2 minute, anterior to and on same pinaculum with SD1; L1 at least $4 \times$ length of L2, on same pinaculum, in line with SD1 (perpendicular with longitudinal axis) or slightly posterior to SD1; L3 about as long as D2, anterior to or in line with D2 perpendicular with longitudinal axis; SV-group bisetose on A1, trisetose (on triangular pinaculum) on A2; MV1 slightly ventral to L3 or in line with L3 parallel with longitidinal axis; V1s on T2 $3 \times$ distance apart as on T3; A3-A6 (Fig. 16) with setae as above except SD1 more anterior to spiracle than on A2; L1 about $4-5 \times$ length of L2; SVgroup trisetose on proleg; crochets bior- dinal except uniordinal and smaller laterally (Fig. 11); V1's slightly farther apart than on A1-A2 and without pinacula (not shown); A7 (Fig. 16) as above except SV-group bisetose, anteroventral to L3; A8 (Fig. 16) as A7 except SD1 ventral to L1-L2 pinaculum, both pinacula anterior to spiracle; L3 hairlike and anterodorsal to SV-group and V1; SV-group bisetose; and spiracle slightly larger than on T1; A9 (Fig. 16) with D2 about $2-3 \times$ longer than D1; D1 slightly anterior to $\mathrm{D} 2$ and SD1; L1 about 5-6× length of L2, both on same pinaculum; L3 hairlike; D2, L1, L3, SV1, and V1 in nearly straight line; anal plate of A10 (Figs. 12, 16) with SD2 and SD1 about equal in lengths, slightly longer than D1; SD1 about $4-5 \times$ farther from SD2 than from D2; D1 slightly shorter than SD1 and SD2, closer to SD1 than to SD2; D2 short and decumbent; proleg with biordinal crochets along mesial margin, smaller and uniordinal crochets along outer margin.

Observations of biology.-We believe that $F$. loowita is univoltine because only larvae were observed in the field during late summer, no adults were observed flying after mid-July, and field collected larvae that were laboratory reared did not pupate until the early summer of the following year. Early instar larvae feed as leaf-miners (Fig. 18), but as larvae grow larger, they move outside of the leaf-mines and incorporate entire leaflets and leaves into their silken feeding tunnels which can extend into the substrate below the plant (Figs. 19-21). Larvae continue to feed only on the mesophyllic layers of the leaflets, leaving behind the yellowish white and hairy upper and lower epidermal layers that help form the walls of their feeding shelters. Lupinus lepidus is also attacked by another leaf-tying larva, Staudingeria albipennella Hulst (Phycitinae: Pyralidae). Damage by $S$. albipennella is indistinguishable from that of $F$. loowita, and 
larvae of both species are often found in the same and/or adjacent feeding tunnels.

Due to the active winds at high elevations on the volcano, adults of $F$. loowita are found resting on or underneath low vegetation or rocks (Fig. 22) and can readily be collected by sweeping near the ground or captured in vials.

As for the recolonization of lupine on Mount St. Helens, we believe that the colonization of $F$. loowita on the volcano came from individuals from sheltered populations within or outside the zone of devastation of the eruption. We also believe that the distribution of this moth species is broader than the data given above, but its range at present is unknown.

Etymology.-The specific epithet, loowita, is derived from Loowit, a name for Mount St. Helens used by the Klickitat, Puyallup, and other native peoples of the Pacific northwest region of the United States.

\section{AcKnowledgments}

We thank Diana Marques, Lisboa, Portugal for the fine computer-generated illustrations of the male and female genitalia, chaetotaxal maps of the larva, and production of the plates; Scott Whittaker, Lab Manager, Scanning Electron Microscopy Laboratory, Smithsonian Institution, Washington, DC, for the suggestions on larval fixation prior to SEM analysis and the scheduling to scope time; and Jon Titus, Department of Biology, SUNY-Fredonia, Fredonia, New York for Fig. 17. This research was supported by NSF grant DEB-008984 to JGB and funding from the M. J. Murdock Charitable Trust. The second author was supported by NSF DEB-008984 while at Washington State University, Vancouver.

\section{Literature Cited}

Busck, A. 1939. Restriction of the genus Gelechia (Lepidoptera: Gelechiidae), with descriptions of new genera. Proceedings of the United States National Museum 86(3064): 563-593.
Clarke, J. F. G. 1941. The preparation of slides of the genitalia of Lepidoptera. Bulletin of the Brooklyn Entomological Society 36: 149-161.

-1947. Notes on, and new species of, American moths of the genus Filatima Busck (Gelechiidae: Lepidoptera). Journal of the Washington Academy of Science 37(8): 263-275.

del Moral, R. 1993. Mechanisms of primary succession on volcanoes: a view from Mount St. Helens, pp. 79-100. In Miles, J. and D. Watson, eds. Primary Succession on Land. Blackwell Scientific, London.

del Moral, R. and L. Bliss. 1993. Mechanisms of primary succession: insights resulting from the eruption of Mount St. Helens. Advances in Ecological Research 24: 1-66.

del Moral, R., J. H. Titus, and A. M. Cook. 1995. Early primary succession on Mount St. Helens, Washington, USA. Journal of Vegetation Science 6: 107-120.

Dethier, V. G. 1941. The antennae of lepidopterous larvae. Bulletin of the Museum of Comparative Zoology: Harvard 87(6): 456-507, 8 plates.

Fagan, W. F. and J. G. Bishop. 2000. Trophic interactions during primary succession: herbivores slow a plant reinvasion at Mount St. Helens. American Naturalist 155: 238-251.

Fagan, W. F., J. G. Bishop, and D. John. 2004. Spatially structured herbivory and primary succession at Mount St Helens: field surveys and experimental growth studies suggest a role for nutrients. Ecological Entomology 29: 398-409.

Germplasm Resources Information Network (GRIN). 2007. United States Department of Agriculture, Agricultural Research Service, Beltsville Area. Website: http://www.ars-grin. gov/cgi-bin/npgs/html/taxon.pl?401686. [Accessed 2 February 2008]

Grimes, L. R. and H. H. Neunzig. 1986. Morphological survey of the maxillae in last stage larvae of the suborder Ditrysia (Lepidoptera): palpi. Annals of the Entomological Society of America 79(3): 491-509.

Hodges, R. L. and D. Adamski. 1997. The identity of Filatima ornatifimbriella (Clemens 1864) (Gelechioidea: Gelechiidae). Journal of the Lepidopterists' Society 51(1): 32-46.

Kornerup, A. and J. H. Wanscher. 1978. Methuen Handbook of Colour. 2nd ed. Methuen and Co., Ltd., London, 243 pp.

Powell, J. A. 2008. Essig Museum of Entomology. University of California, Berkeley, Database, http://essig.berkeley.edu/leplist/gelechi.html. [Accessed 29 June 2008] 
Robinson, G. S., P. R. Ackery, I. J. Kitching, G. W. Beccaloni, and L. M. Hernández. 2002. Hostplants of the moth and butterfly caterpillars of America north of Mexico. Memoirs of the American Entomological Institute 69. 824 pp.
Stehr, F. W. 1987. Immature Insects. Kendall/Hunt Pub. Co., Dubuque, Iowa, xiv +754 pp.

Wood, D. M. and R. del Moral. 1987. Mechanisms of early primary succession in subalpine habitats on Mount St. Helens. Ecology 68: 780-790. 